\title{
Wykaz publikacji Profesora Andrzeja Sitarskiego
}

\author{
List of publications by Professor Andrzej Sitarski
}

\section{Monografie}

Pol'skâ̂ i russkaâ lingvističeskâ̂ terminologiâ v svete slovoobrazovatel'nogo i leksičeskogo âvlenij. Poznań, Wydawnictwo Naukowe UAM, 1991.

Struktura i funkcionirovanie narečij v russkom âzyke novejšego vremeni. Poznań, Wydawnictwo Naukowe UAM, 2001.

\section{Artykuły}

„O kompresji strukturalnej w zakresie polskiej i rosyjskiej terminologii językoznawczej". Studia Rossica Posnaniensia, 16, 1981, s. 183-191.

„O synonimii w polskiej i rosyjskiej terminologii językoznawczej”. Przegląd Rusycystyczny, 4, 1981, s. 68-72.

„Polska i rosyjska terminologia językoznawcza w świetle zjawisk leksykalnych i słowotwórczych języka polskiego i rosyjskiego". Przegląd Rusycystyczny, $1-2,1984$, s. 187-192.

„Zjawisko antonimii w sferze słownictwa naukowego (na przykładzie polskiej i rosyjskiej terminologii językoznawczej)". Studia i Materiały XXVIII, Filologia Rosyjska, 7, 1988, s. 149-156.

„Zjawisko homonimii w polskiej i rosyjskiej terminologii językoznawczej”. Studia Rossica Posnaniensia, 20, 1988, s. 197-201.

„O apelatywach odantroponimicznych w leksyce języka polskiego i rosyjskiego". Studia i Materiaty XXX, Filologia Rosyjska, 8, 1989, s. 71-79.

„O polskich i rosyjskich terminach językoznawczych powstałych w rezultacie derywacji semantycznej”. Studia i Materiaty XXXV, Filologia Rosyjska, 9, 1990, s. 187-191.

„Internacjonalizacja w zakresie polskiej i rosyjskiej terminologii językoznawczej”. Studia Rossica Posnaniensia, 22, 1991, s. 171-177. 
„O apelatywach odantroponimicznych w najnowszym słownictwie rosyjskim”. Małe formy w literaturze rosyjskiej, słowo $w$ tekście rosyjskim: językoznawstwo. Red. Walenty Piłat. Olsztyn, Wydawnictwo WSP w Olsztynie, 1991, s. $107-114$.

„O zapożyczeniach leksykalnych z języka rosyjskiego we współczesnym języku polskim i bułgarskim". II Kolokwium Slawistyczne Polsko-Bułgarskie. Red. Jerzy Świdziński, Tadeusz Zdancewicz. Poznań, Wydawnictwo Poznańskiego Towarzystwa Przyjaciół Nauk, 1991, s. 169-175 (z Eugenią Stankiewicz-Walter).

„O precyzji strukturalno-semantycznej terminu naukowego (na przykładzie polskiej i rosyjskiej terminologii językoznawczej)”. Problemy stylu naukowego i terminologii. Prace Naukowe Studium Nauki Języków Obcych Politechniki Wroctawskiej 28. Seria Studia i Materiaty, 24, 1992, s. 25-35.

„Apellâtivaciâ antroponimov v sovremennom russkom âzyke”. Studia Rossica Posnaniensia, 24, 1993, s. 139-144.

„Slovoobrazovatel'naâ harakteristika novyh russkih narečij”. Studia Rossica Posnaniensia, 28, 1998, s. 123-128.

„Sopostavitel'nyj analiz pol'skih, russkih i anglijskih frazeologizmov, soderžaŝih v svoem sostave nazvanie životnogo". Izbrannye aspekty izučeniâ russkogo âzyka i literatury. Red. Antoni Markunas. Poznań, Wydawnictwo Naukowe UAM, 1998, s. 49-55 (z Wiesławą Muzal).

„Iz nablûdenij nad funkcionirovaniem narečij v sovremennom russkom i pol'skom âzykah". Acta Polono-Ruthenica, 4, 1999, s. 143-149.

„Semantiko-sintaksičeskaâ funkciâ narečiâ v sovremennom russkom âzyke”. Rusistika i sovremennost'. Ázykoznanie. Red. Marian Bobran. Rzeszów, Wydawnictwo Wyższej Szkoły Pedagogicznej, 1999, s. 195-202.

"Apellâtivnye derivaty ot imen sobstvennyh v novejšej leksike russkogo âzyka”. Kieleckie Studia Rusycystyczne, 10, 2000, s. 203-209.

„K voprosu o semantiko-sintaksičeskoj funkcii narečij v russkom i pol'skom âzykah (na materiale poèmy V. Erofeeva Moskva-Petuški i ee pol'skogo perevoda)". Acta Polono-Ruthenica, 5, 2000, s. 219-225.

„K voprosu o vnutrennem razvitii i slovoobrazovanii narečij v sovremennom russkom âzyke". Acta Universitatis Wratislaviensis 2191. Slavica Wratislaviensia, 107, 2000, s. 101-106.

„K voprosu o funkcionirovanii narečij v russkom âzyke novejšego vremeni”. Èkologiâ kul'tury - žizn' âzyka. Meždunarodnyj sbornik naučnyh statej. Red. Tat'âna Nikolaevna Pleškova. Arhangel'sk, Pomorskij gosudarstvennyj universitet im. M. V. Lomonosova, 2001, s. 83-89.

„K voprosu o semantike sovremennyh russkih narečij”. Rusistika i sovremennost'. Âzykoznanie 2. Red. Marian Bobran. Rzeszów, Wydawnictwo Wyższej Szkoły Pedagogicznej, 2001, s. 97-105. 
„Narečiâ otnošeniâ v novejšej leksike”. Innowacje w językach wschodniosłowiańskich II. Red. Bazyli Tichoniuk. Zielona Góra, Uniwersytet Zielonogórski, 2002, s. 91-98.

„Narečiâ v russkih i pol'skih gazetnyh zagolovkah”. Acta Polono-Ruthenica, 7, 2002, s. 125-131.

„Ob upotreblenii ustojčivyh slovosočetanij v gazetnyh zagolovkah (na materiale sovremennoj russkoj i pol'skoj pressy)". Rusistika i sovremennost'. Ázykoznanie 3. Red. Marian Bobran. Rzeszów, Wydawnictwo Uniwersytetu Rzeszowskiego, 2003, s. 116-123.

„K voprosu o nekotoryh tendenciâh v razvitii leksičeskogo zapasa sovremennogo russkogo âzyka: (na primere komp'ûternoj leksiki i leksiki šou-biznesa)". Acta Polono-Ruthenica, 9, 2004, s. 263-271.

„K voprosu ob anglicizmah v semantičeskom pole «kul'tura» v sovremennom russkom âzyke". Wyraz i zdanie w językach słowiańskich 4. Opis, konfrontacja, przekład. Red. Iwona Łuczków, Jan Sokołowski. Wrocław, Wydawnictwo Uniwersytetu Wrocławskiego, 2004, s. 249-256.

„Sobstvennye imena v âzyke sovremennoj russkoj pressy”. Słowo, tekst, czas VII. Nowe środki nominacji językowej w nowej Europie. Novye sredstva âzykovoj nominacii v novoj Evrope. Neue Mittel der Sprachnomination in neuem Europa. Red. Michaił Aleksiejenko, Marzanna Kuczyńska. Szczecin, Wydawnictwo Naukowe Uniwersytetu Szczecińskiego, 2004, s. 155-160.

„K voprosu o slovoobrazovatel'noj harakteristike russkogo komp'ûternogo žargona". Studia Rusycystyczne Akademii Świętokrzyskiej, 15, 2005, s. 125-130. „Ob aksiologičeskom aspekte âzyka političeskoj informacii (na materiale sovremennoj rossijskoj pressy". Wyraz i zdanie w językach słowiańskich 5. Opis, konfrontacja, przekład. Red. Michał Sarnowski, Włodzimierz Wysoczański. Wrocław, Wydawnictwo Uniwersytetu Wrocławskiego, 2005, s. 333-338.

„Opyt lingvističeskogo opisaniâ ocenočnyh vyskazyvanij i ih pol'skih perevodnyh èkvivalentov v âzyke Anny Arkad'evny Kareninoj”. Lew Totstoj i kultury słowiańskie. Red. Bazyli Białokozowicz. Olsztyn, Wydawnictwo Uniwersytetu Warmińsko-Mazurskiego, 2005, s. 229-237.

„Słowiańszczyzna wschodnia w pracy naukowej i dydaktycznej Profesora Tadeusza Zdancewicza”. Z mała ojczyzna w sercu. Księga pamiątkowa dedykowana Profesorowi Tadeuszowi Zdancewiczowi. Red. Mariola Walczak-Mikołajczakowa, Bogusław Zieliński. Poznań, Wydawnictwo Naukowe UAM, 2005, s. 27-33.

„Lingvističeskie sredstva realizacii kategorii ocenočnosti v âzyke sovremennoj russkoj reklamy". Russkij âzyk: sistema i funkcionirovanie (k 80-letîu professora P. P. Šuby). Materialy III Meždunarodnoj naučnoj konferencii. Minsk, 6-7 apr. 2006 g.: v 2 č. Minsk, RIVŠ, 2006, cz. 1, s. 161-164. 
„K voprosu o modelirovanii aksiologičeskogo soznaniâ (na materiale âzyka reklamy). Język, człowiek, dyskurs. Red. Mirosława Hordy, Walerij Mokijenko, Harry Walter. Szczecin, Print Group Daniel Krzanowski, 2007, s. 577582.

„K voprosu ob ocenočnom âzyke sovremennoj russkoj reklamy. Na materiale tekstov reklamy kosmetičeskih izdelij”. Acta Polono-Ruthenica, 12, 2007, s. $211-218$.

„Koncept «den'gi» v cennostnoj kartine mira. Na materiale frazeologizmov i poslovic russkogo i pol'skogo âzykov". Poznan'-Arhangel'sk: desât' let sotrudničestva. Sbornik naučnyh statej. Red. Tat'âna Nikolaevna Pleškova. Arhangel'sk, Pomorskij gosudarstvennyj universitet im. M. V. Lomonosova, 2007, s. $46-53$.

„Miejsce i ranga przysłówków we współczesnym języku rosyjskim”. Studia nad stownictwem dawnym $i$ wspótczesnym języków słowiańskich. Red. Joanna Kamper-Warejko, Iwona Kaproń-Charzyńska, Joanna Kulwicka-Kamińska. Toruń, Wydawnictwo Uniwersytetu Mikołaja Kopernika, 2007, s. 181-186.

„Aksiolingvističeskaâ kartina sovremennoj dejstvitel'nosti v tekstah rossijskih hiphopovcev". Acta Polono-Ruthenica, 13, 2008, s. 487-496.

„K voprosu ob aksiologičeskoj konnotacii russkih frazeologizmov i poslovic s komponentami: «zoloto» i «zolotoj»". Rossica Olomucensia XLVI-II. Sborník přispěvků z mezinárodní konference XIX. Olomoucké dny rusistü-30.08.01.09.2007. Olomouc, 2008, s. 409-412.

„Medial'naâ kartina Pol'ši - lingvo-aksiologičeskij analiz. Na materiale tekstov sovremennoj russkoj pečati”. Wyraz i zdanie w językach stowiańskich 6. Opis, konfrontacja, przekład. Red. Michał Sarnowski, Włodzimierz Wysoczański. Wrocław, Wydawnictwo Uniwersytetu Wrocławskiego, 2008, s. 409-417.

„K voprosu o realizacii âzykovogo ûmora v tekste sovremennoj pol'skoj i russkoj reklamy". Wyraz i zdanie w językach stowiańskich 7. Opis, konfrontacja, prze$k ł a d$. Red. Michał Sarnowski, Włodzimierz Wysoczański. Wrocław, Wydawnictwo Uniwersytetu Wrocławskiego, 2009, s. 241-249.

„Karnaval'naâ koncepciâ mira i čeloveka v aksiologičeskom aspekte: (na materiale izbrannyh russkih i pol'skih frazeologičeskih edinic)". Acta Polono-Ruthenica, 14, 2009, s. 497-503.

„Antropocentrizm v semantike âzykovyh edinic (na materiale russkih frazeologizmov i paremij so značeniem «uspeh»)". $Z$ zagadnień semantyki $i$ stylistyki tekstu. Red. Anna Ginter. Łódź, Wydawnictwo Uniwersytetu Łódzkiego, 2010, s. 275-283.

„Koncept «vremâ» v russkom i pol'skom âzykovom prostranstve (na materiale russkih i pol'skih frazeologizmov s komponentom «vremâ»/《czas» i «den'»/ «dzień»”. Studia Rossica Posnaniensia, 35, 2010, s. 267-273. 
„Ob aksiologičeskoj interpretacii russkih i pol'skih frazeologičeskih edinic, otnosâsihsâ k konceptu «âzyk»". Meninis tekstas: Suvokimas. Analizė. Interpretacija, 7, 2010, s. 137-143.

„Zamierzenia perspektywiczne Filologii Ukraińskiej na Uniwersytecie im. Adama Mickiewicza w Poznaniu". Zakład Ukrainistyki: perspektywy, teraźniejszość, przeszlość (z okazji 20-lecia istnienia): opracowanie naukowe. Red. Andrzej Sitarski, Tetyana Kosmeda. Poznań, Instytut Filologii Rosyjskiej UAM, 2011, s. 7-9.

„Poznańska przestrzeń i czas Profesora Zbigniewa Barańskiego". Mistrzowi i Przyjacielowi. Pamięci Profesora Zbigniewa Barańskiego. Red. Anna Paszkiewicz, Elżbieta Tyszkowska-Kasprzak, Wiesława Zybura. Wrocław, GAJT Wydawnictwo, 1991 s.c., 2010, s. 63-66.

„Frazeologičeskie edinicy v funkcii aksiologičeskogo parametra âzyka sportivnogo kommentariâ”. Współczesne badania nad kultura, literatura i językiem rosyjskim. Red. Dorota Paśko-Koneczniak. Toruń, Wydawnictwo Naukowe Uniwersytetu Mikołaja Kopernika, 2012, s. 361-369.

„Lingvoaksiologičeskoe prostranstvo leksem, oboznačaûsìh nebesnye tela (na materiale frazeologičeskih edinic pol'skogo i russkogo âzykov)". Stowo, tekst, czas XI. Frazeologia stowiańska w aspekcie onomazjologicznym, lingwokulturologicznym i frazeograficznym. Red. Mirosława Hordy et al. SzczecinGreifswald, Zapol, 2012, s. 277-282.

„Ocenočnaâ funkciâ antroponimov (na materiale âzyka sovremennoj russkoj pressy)". Zeszyty Naukowe Wyższej Szkoły Języków Obcych w Świeciu, 2, 2012, s. $120-125$.

„Z człowiekiem w sercu. O Pani Profesor Tatianie Kosmedzie w związku z Jubileuszem”. Kosmeda Tetâna Anatolï̈vna. Biobibliografičnij pokažčik. Red. İrina Kočan, Anna Gornâtko Šumilovič. Drogobič, Kolo, 2012, s. 16-17.

„O kategorizacii ponâtiâ «zemlâ» v semantiko-kul'turologičeskom aspekte: na materiale russkih i pol'skih frazeologizmov s leksičeskim komponentom «zemlâ»/«ziemia»”. Studia Rossica Posnaniensia, 38, 2013, s. 245-252.

„Język rosyjski a komunikacyjne wyzwania współczesności”. Zeszyty Naukowe Wyższej Szkoły Języków Obcych w Świeciu, 3, 2014, s. 241-251.

„K voprosu ob aksiologizacii âzyka pravoslavnoj propovedi (na materiale tekstov Mitropolita Savvy Slova i propovedi)". Imiona komunikacji językowej, czyli demakijażowanie sensów: księga jubileuszowa dedykowana Profesor Marcelinie Grabskiej. Red. Katarzyna Wojan, Żanna Sładkiewicz, Anna Hau, Katarzyna Wądołowska-Lesner. Gdańsk, Wydawnictwo Uniwersytetu Gdańskiego, 2015, s. 113-118.

„Atributivnye kollokacii, kak istočnik âzykovoj èksplikacii koncepta «lûbov'» v russkom lingvokul'turologičeskom prostranstve". Acta Polono-Ruthenica, 21, 2016, s. 89-97. 
„Emocjonalizmy jako afektywne źródło wartościowania rzeczywistości (na podstawie polskiego thumaczenia poematu Uładzimira Niaklajeua Turma z tomu wierszy Listy do Violi)”. Emocje w językach i kulturach świata. Red. Ewa Komorowska, Agnieszka Szlachta. Szczecin, Volumina.pl Daniel Krzanowski, 2016, s. 341-346.

„Paradygmat antropocentryczny jako kategoria lingwistyczna w badaniu obiektów językowych". Studia Rossica Posnaniensia, 41, 2016, s. 419-425.

„ÂAykovaâ realizaciâ mikrokonceptov «otec», «syn»//«ojciec», «syn» v russkom i pol'skom lingvokul'turnom prostranstve". Wyraz $i$ zdanie $w$ językach stowianskich 9. Opis, konfrontacja, przekład. Red. Włodzimierz Wysoczański, Bogumił Gasek. Wrocław, Wydawnictwo Uniwersytetu Wrocławskiego, 2017, s. 349-356.

„Segment frazeologiczny i paremiologiczny pola konceptualnego «pracowitość»/ «trudolûbie» w języku polskim i rosyjskim”. Scripta Neophilologica Posnaniensia, 17, 2017, s. 301-307.

„Językowe emanacje emocji w Listach do Violi Vładzimira Naklajeva jako źródło wartościowania rzeczywistości”. Acta Polono-Ruthenica, 23 (3), 2018, s. 119-124.

„Prezentacja frazeologiczna pola konceptualnego «Pamât'»/〈Pamięć» w języku rosyjskim i polskim”. Studia Rossica Posnaniensia, 43, 2018, s. 289-295.

„Pole frazeosemantyczne konceptu «władza»/«vlast’» we współczesnym języku polskim i rosyjskim". Acta Neophilologica, 21 (2), 2019, s. 57-64.

\section{Recenzje}

„«Współczesny język rosyjski. System gramatyczny (z ćwiczeniami)», Czesław Lachur, Opole 1998: [recenzja]". Acta Polono-Ruthenica, 4, 1999, s. 402-405 (z Tamarą Uczitiel).

„«Političeskij fel'eton v svete teorii rečevogo vozdejstviâ», Žanna Sladkevič, Gdańsk 2013: [recenzja]”. Studia Rossica Gedanensia, 1, 2014, s. 497-498.

\section{Wydawnictwa z zakresu dydaktyki języka rosyjskiego}

Bogacka, Barbara, Andrzej Sitarski. Intensywny kurs języka rosyjskiego (24-kasetowy wraz z zeszytami). Poznań, Merimpex i Polskie Radio Poznań, 1984.

Glinka, Marian, Irena Kotwicka-Dudzińska, Andrzej Narloch, Andrzej Sitarski. Uniwersalny stownik rosyjsko-polski i polsko-rosyjski 40000 haset i zwrotów). Poznań, Wydawnictwo LektorKlett, 2006.

Kotwicka-Dudzińska, Irena, Iwona Wapnaruk-Sitarska, Andrzej Sitarski. Rosyjski: intensywny kurs do samodzielnej nauki. Poznań, SuperMemo World, 2008. 


\section{Tłumaczenia na język rosyjski i z języka rosyjskiego (wydania książkowe)}

Nacional'nyj muzej v Poznani. Przeł. Andrzej Sitarski. Poznań, Muzeum Narodowe, 1979.

Polska sztuka współczesna w zbiorach Muzeum Narodowego w Poznaniu. Red. Henryk Kondziela. Przeł. Andrzej Sitarski. Poznań, Muzeum Narodowe, 1985. Trubnikow, Borys. Wielki leksykon broni i uzbrojenia. Przeł. Olga Makarowska, Andrzej Sitarski. Poznań, Wydawnictwo Kurpisz, 2000.

Wiszniewska, Galina. Galina. Historia mojego życia. Przeł. Andrzej Sitarski.

Poznań, Teatr Wielki im. S. Moniuszki, 2000.

Pręgowski, Stanisław. Ludzie i kamienie. Przeł. Andrzej Sitarski. Poznań, Wydawnictwo Kurpisz, 2001.

Wildemann, Victoria. Rosyjski w 1 miesiąc. Przeł. Andrzej Sitarski. Poznań, Wydawnictwo LektorKlett, 2003. 